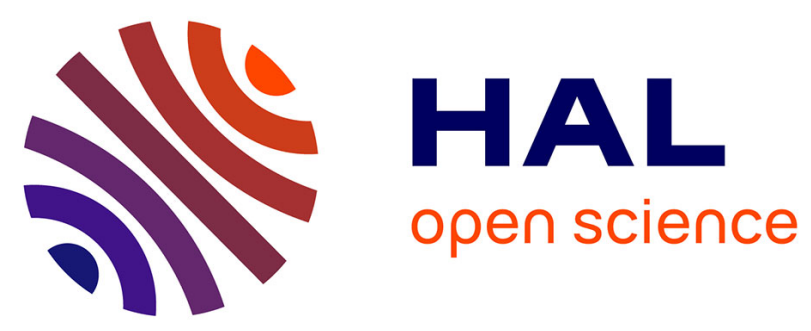

\title{
Nutritional status of Amerindian children from the Beni River (lowland Bolivia) as related to environmental, maternal and dietary factors
}

Eric Bénéfice, Selma Luna Monrroy, Sonia Jimenez, Ronald Lopez

\section{- To cite this version:}

Eric Bénéfice, Selma Luna Monrroy, Sonia Jimenez, Ronald Lopez. Nutritional status of Amerindian children from the Beni River (lowland Bolivia) as related to environmental, maternal and dietary factors. Public Health Nutrition, 2006, 9 (3), pp.327-335. 10.1079/PHN2006852 . ird-00192477

\section{HAL Id: ird-00192477 https://hal.ird.fr/ird-00192477}

Submitted on 28 Nov 2007

HAL is a multi-disciplinary open access archive for the deposit and dissemination of scientific research documents, whether they are published or not. The documents may come from teaching and research institutions in France or abroad, or from public or private research centers.
L'archive ouverte pluridisciplinaire HAL, est destinée au dépôt et à la diffusion de documents scientifiques de niveau recherche, publiés ou non, émanant des établissements d'enseignement et de recherche français ou étrangers, des laboratoires publics ou privés. 


\title{
Nutritional status of Amerindian children from the Beni River (lowland Bolivia) as related to environmental, maternal and dietary factors
}

\author{
Eric Benefice $^{1, *}$, Selma Luna Monroy ${ }^{2}$, Sonia Jiménez ${ }^{2}$ and Ronald López ${ }^{1,2}$ \\ 'Epidemiology \& Prevention Research Unit (R024), Representación Institut de Recherche pour le Développement \\ (IRD, France) de Bolivia, Av. Hernando Siles \#5290, Esq Calle 7 Obrajes, PB 9214, La Paz, Bolivia: ${ }^{2}$ Instituto \\ SELADIS (Facultad de Ciencias Farmacéuticas y Bioquímicas), Universidad Mayor de San Andrés, La Paz, Bolivia
}

Submitted 14 March 2005: Accepted 18 July 2005

\begin{abstract}
Objectives: To report the nutritional status of children aged up to 15 years and their mothers living in a remote Amazonian area of Bolivia, and to study its main social, familial and maternal determinants.

Setting: Fifteen Beni River communities located at the foot of the Andes.

Design: Cross-sectional survey of riverside populations. All childbearing mothers and their children in the 15 communities were examined.

Methods: Information on household production, dietary habits and demography was collected. Individual clinical, anthropometric and parasitological examinations were carried out.

Subjects: A total of 631 persons were examined: 171 mothers and 460 children and adolescents aged 0 to 15 years.

Results: There were no cases of severe wasting, but $41 \%$ of $0-5$-year-olds and $36 \%$ of 5-10-year-olds were stunted. Among 346 stool specimens examined, 75\% were positive for at least one helminth. Diversity of food and quality of diet were satisfactory in $54 \%$ of households, but $27 \%$ had low diversity scores. Mothers were lighter and shorter than those observed at the national level: 20\% had height below $145 \mathrm{~cm}$. Prevalence of anaemia (42\%) was also higher. In pre-school children, multivariate analysis indicated a relationship between growth retardation and household factors such as dietary quality, ethnic group and clinical state, but not maternal anthropometry. In contrast, in school-age children and adolescents, growth retardation was related to maternal characteristics.

Conclusions: Growth retardation appeared mainly during the weaning period and did not seem to improve thereafter. To ameliorate this situation, an effort should be made to prevent common parasitic and infectious diseases in young children. Follow-up of pregnant mothers during pregnancy and delivery also needs to be reinforced.
\end{abstract}

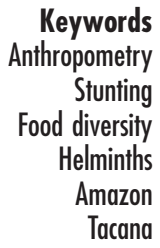

Social vulnerability is linked to ill health and malnutrition. This is particularly worrisome for certain segments of the population undergoing rapid economic transformation or environmental degradation ${ }^{1}$. The nutritional and growth status of rural children in Latin America is changing rapidly $^{2}$. While improvements in food intake have been observed, malnutrition remains ${ }^{3,4}$. A recent survey comparing the situation in four Andean countries (Colombia, Ecuador, Peru and Bolivia) stressed the strong relationship between chronic malnutrition, represented by stunted growth, and low socio-economic status ${ }^{5}$, affecting mainly indigenous children. In Bolivia, analysis of Demographic and Health Surveys (DHS) indicates that chronic malnutrition has decreased by more than $13 \%$ in 10 years ( 1989 to 1998). However, progress has not been evenly distributed, and profound differences exist between rural and urban areas (stunting prevalence: $35.6 \%$ rural vs. $18.3 \%$ urban) ${ }^{6}$. The prevalence may be even higher in indigenous groups, as suggested by a recent investigation carried out in the Amazon region which reported a prevalence of chronic malnutrition of $43-52 \%$ among the Tsimane ${ }^{7}$.

Anthropometry is the most simple and reliable method for characterising nutritional status. While the construction of nutritional indices is straightforward, their interpretation is subject to caution. In young children, dietary deficit is not the only cause of malnutrition; infectious and parasitic diseases also play an important role ${ }^{8}$. For this reason, anthropometry is a useful tool for quantifying and evaluating the status of groups living in remote areas and lacking health facilities. 
Determinants of malnutrition have several dimensions (socio-economic, environmental and biological); among these, familial factors and single mother status warrant special attention?. The nutritional status of children is dependent on prenatal factors (intrauterine growth restriction) as well as factors operating during infancy and childhood, and these may vary during the different periods ${ }^{10}$. The causes and effects of malnutrition are subject to change over the years. To understand such changes, it is important to include other age groups, along with pre-school children, in the analysis.

Thus, the objective of the present paper is twofold: (1) to provide an update on the nutritional status of indigenous children, adolescents and their mothers living on the banks of the Beni River (Bolivia); and (2) to examine risk factors, especially family-related variables, that might explain this situation.

\section{Methods}

\section{Context}

The Beni River is the Andean headwater of the Rio Madeira, one of the four most important tributaries of the Amazon River. There is growing concern about mercury contamination of the Beni Basin. As a consequence, it was decided to carry out a multidisciplinary research project in the area. Within this framework, a general health and nutritional survey was performed on the riverside population along the Beni River, from the edge of the Andean piedmont until $120 \mathrm{~km}$ downstream. All communities found downriver from the town of San Buenaventura, 15 in total, were visited in four rounds between March and August 2004.

\section{Study population}

The population of rural areas in which the survey was performed was 14000 (estimated from the 2001 census $^{11}$ ). However, only about 4000 persons actually live on the banks of the Beni River. The sample size was chosen on the basis of an anticipated prevalence of chronic malnutrition of $35 \%$ in $0-10$-year-old children. This value was derived from the prevalence of $35.6 \%$ for rural Bolivia ${ }^{6}$. A theoretical calculation showed that at least 364 children were required to obtain 5\% precision, with a 95\% confidence interval (CI). Taking into account the dispersion and frequent displacement of populations along the Beni River for fishing and logging activities, we decided to incorporate all mothers and their children up to 15 years of age present in the communities at the time of our visits. A total of 631 persons (171 mothers and 460 children) were examined. The total number of $0-10$-year-old children, i.e. 354, was slightly less than expected, but this did not change the precision. In all, six children had incomplete anthropometric data, thus some analyses were done with 454 children.

Most of the inhabitants belonged to the Pueblo Tacana tribe (148 families out of 171). This is a small ethnic group estimated at from 5000 to 7000 persons. Most of the communities came from the town of San Buenaventura, settled at the foot of the Andean cordillera, established through the 'reducciones' system by Franciscan missionaries. The Tacana are well integrated into Bolivian society. They use Spanish as their common language. They grow tubers (cassava root), plantains, rice and maize for subsistence $^{12}$. They work as woodcutters for cash. They continue to obtain a substantial part of their animal food through hunting and fishing. A minority of households were constituted by the Esse Ejja ethnic group ( 23 families out of 171). This group eventually settled along the Beni River. Esse Ejja belong to the same linguistic family as the Tacana. However, they are far less well integrated. They speak Tacana, and only a few men are literate and know Spanish. Fishing constitutes their main activity; they also cultivate rice and cassava. They sell their surplus fish in the cities for income. They appear to be more vulnerable and unprotected than the Tacana when confronted with economic developers or tour operators. Both groups live in wooden houses without a concrete floor and roofs comprising matted palm fronds. The surrounding vegetation is cleared and houses are generally kept clean inside and outside. However, domestic animals, i.e. dogs, pigs and chickens, run free in the villages. Public infrastructures are limited: when ill, inhabitants are required to travel for long hours upstream to receive treatment at local hospitals. Contacts between villages are maintained through radio broadcast. The education commitment is remarkable: schools existed in 12 of the 15 communities visited. In most cases, teachers serve as health agents, public health advisers and even midwives.

\section{Ethical considerations}

The study protocol was approved by the SELADIS (Instituto de Servicios de Laboratorio de Diagnostico e Investigación en Salud, Universidad Mayor de San Andrès de La Paz) review board and then by the Comité Nacional de Bioética (La Paz, Bolivia) and the Comité Consultatif de Déontologie et d'Ethique (CCDE, IRD, France). The aims of the study were individually notified to each patient, or their parents in the case of children. They signed an informed consent form. In the case of illiterate persons, a bona fide witness signed the form after the subject gave oral consent.

\section{Study variables}

The study consisted of a health and nutritional survey, complemented by data on dietary habits and household economic activities. Mothers were questioned in Spanish about the main activity and characteristics of the household, i.e. agriculture, fishing and hunting, woodcutter. Their reproductive history was also noted. They responded to a dietary recall. The questionnaire recapitulated the main dishes consumed during the last $24 \mathrm{~h}$ and food items consumed on a daily, weekly and monthly basis and allocated into seven groups (fish, cereals, tubers, plantain, 
fruits, meat and milk). A food diversity index (FDI) was elaborated to record the presence or absence of consumption of a food group. For better sensitivity, weighting was introduced according to the nutritional value of each food group:

- Group 1 - fish, meat and milk (value 4).

- Group 2 - cereals (value 3).

- Group 3 - fruits (value 2).

- Group 4 - tubers and plantains (value 1).

This weighted index had a maximum value of 19 .

Subjects underwent a medical examination to detect whether they suffered from a clinically detectable illness. Blood pressure was taken with a sphygmomanometer with a strap adapted for age. Anthropometric measurements were then carried out. They consisted of measurement of:

1. Weight $(\mathrm{kg})$ recorded with an electronic adult scale $\left(\right.$ Seca $^{\circledR}$ ) accurate to $100 \mathrm{~g}$ or with an infant electronic scale $\left(\right.$ Seca ${ }^{\circledR}$ ) accurate to $10 \mathrm{~g}$ for children less than 2 years of age.

2. Recumbent length $(\mathrm{cm})$ measured with a wooden board (accuracy: $1 \mathrm{~mm}$ ) for children less than 2 years old; for older children and mothers, standing height (cm) was measured with a Harpenden ${ }^{\circledR}$ anthropometer (accuracy: $1 \mathrm{~mm}$ ).

3. Four subcutaneous skinfold thicknesses ( $\mathrm{mm}$ ) measured at the following sites: triceps, biceps, subscapular and suprailiac; all measurements were taken on the left side with a Holtain ${ }^{\circledR}$ calliper and were done in duplicate according to recommended techniques $^{13}$

Measurements were taken by two persons (E.B., S.L.) after standardisation and regular calibration.

The following anthropometric indices were calculated using Anthro software (Centers for Disease Control and Prevention, Atlanta, GA, USA): height-for-age, weight-forage and weight-for-height. Stunting was defined as heightfor-age below minus two standard deviations $(<-2 \mathrm{SD})$ from the median of the World Health Organization (WHO)/National Center for Health Statistics (NCHS) reference $^{14}$ (height-for-age $Z$-score $<-2$ ); wasting as weight-for-height $<-2 \mathrm{SD}$ from the WHO/NCHS reference median (weight-for-height $Z$-score $<-2$ ); and underweight as weight-for-age $<-2 \mathrm{SD}$ from the WHO/ NCHS reference median (weight-for-age $Z$-score $<-2$ ). Body mass index (BMI, $\mathrm{kg} \mathrm{m}^{-2}$ ) was computed as weight divided by the square of height. It was used as a wasting or corpulence index in adult mothers and children over 10 years of age. The sum of the four skinfold thicknesses was used as an index of adiposity.

Stool specimens were obtained from children and adolescents for determination of parasites. Stools were examined on site, immediately after emission, in saline solution. Then a portion of the stool was preserved in 10\% formalin solution and taken to the parasitological laboratory of SELADIS in La Paz for enrichment using a formalin-ether/ethyl acetate procedure after centrifugation. The presence of helminths in stools after enrichment was used as an index of parasite infestation. It was not the purpose of this paper to analyse parasitism in detail, but rather to focus on geo-helminths known to have an impact on childhood nutritional status ${ }^{15}$.

Finally, a drop of blood was taken at the finger pulp of mothers for analysis of its haemoglobin content using a HemoCue ${ }^{\circledR} \mathrm{AB}$ portable spectrophotometer (Ångelhom, Sweden).

\section{Statistical analyses}

Data entry and clearance were performed using Epi Info software (Centers for Disease Control and Prevention, 2004). Statistical analysis was done using SPSS 11.01 (SPSS Inc., Chicago, IL, USA, 1989-2001) and NCSS (Hintze J, 2001) software. Data variability is presented as either mean \pm SD in the case of continuous variables or frequency (95\% CI) for categorical variables. The influence of maternal or familial characteristics on the nutritional status of preschool children $(<5$ years), school-age children (5-10 years) and adolescents (10-15 years) was first identified using means comparison and correlation tests. Following this, a multiple regression analysis was done with the NCSS package that allows the entry of categorical variables. The nutritional status of children (stunting) was used as a dependent variable, and clinical, familial and maternal characteristics as independent variables. The probability level of significance was set at $P<0.05$.

\section{Results}

\section{Dietary patterns}

Almost all families ate three meals per day; 10 families (5.8\%, 95\% CI: $2.8-10.5 \%)$ did not have dinner. A variety of dishes was prepared: 56 different items were reported for breakfast, 44 for lunch and 59 for dinner. However, the most frequently consumed dish consisted of a combination of rice with meat or fish. Meat came from wild animals in 107 cases (63\%) and from cows or pigs in 53 cases (31\%). Thirty-three families (19\%) ate fish on a daily basis and 103 (60\%) every week. The four most frequently consumed fish were sabalo (Prochilodus nigricans), pacu (Colossoma macropomum), pintado (Pseudoplastystoma fasciatum) and palometa (Pygocentrus nattereri). Most families $(123,72 \%)$ consumed small quantities of milk in the form of powder. Rice was the most commonly consumed cereal (162 families, 95\%); 108 families (63\%) consumed cassava daily; potatoes were eaten by only six families. Plantains were eaten daily by 163 families (95\%), as were fruits, eaten by 150 families (88\%). Oranges (85\%) and grapefruit (32\%) were the most frequently consumed fruits of the season. Finally, 92 families (54\%, 95\% CI: 
46.0-61.4\%) had an FDI score greater than 14 (range: $1-19$, mean: $13.6 \pm 3.0$ ), indicating a good balance among the different food groups. However, 46 families (27\%, 95\% CI: 20.4-34.2\%) had an FDI score less than 11 , denoting a monotonous diet and scarceness of foods of animal origin.

\section{Maternal characteristics}

Given their isolation, it is not surprising that only 20 mothers out of 163 with complete information (12\%, 95\% CI: 6.6-16.8\%) gave birth in hospital; 113 (69\%, 95\% CI: 61.6-76.2\%) gave birth alone or with the support of the husband or mother. Only 32 mothers (20\%, 95\% CI: 13.9-26.5\%) were attended by a midwife. A total of 143 mothers (88\%, 95\% CI: 81.7-92.3\%) gave birth at home. Women breast-fed their children during the first year of life (mean age of weaning: 16.8 \pm 6.5 months). Only nine children were breast-fed for less than 6 months. Complementary foods, generally gruel of plantain or cassava, were not introduced before 1 year of age.

Table 1 displays sociodemographic and physical characteristics of the mothers. One mother was only 15.5 years old while another was 70 years old. This woman was the grandmother and was nurturing the children of her daughter, who had died. As a whole, the sample was constituted by young persons. In all, the mothers gave birth to 1073 children. Of these, 851 survived (79\%, 95\% CI: 76.7-81.7\%) and 222 died during childhood or infancy (21\%, 95\% CI: 18.3-23.2\%). Fifty per cent of mothers had lost at least one child. Blood pressures were low in this population: only one woman, with a systolic blood pressure higher than $160 \mathrm{mmHg}$, could be considered hypertensive.

Table 2 compares data from the present survey with those of the $\mathrm{DHS}^{6}$. Women in our sample were shorter and lighter than women at both national and local levels. The prevalence of women of short stature (less than $145 \mathrm{~cm}$ ) or low BMI $\left(<18.5 \mathrm{~kg} \mathrm{~m}^{-2}\right)$ was also higher. Interestingly, 67

Table 1 Characteristics of Beni River mothers $(n=171)$

\begin{tabular}{lrrc}
\hline & Mean & SD & $\begin{array}{c}\text { Median } \\
\text { (min-max) }\end{array}$ \\
\hline Age (years) & 34.7 & 13.1 & $32.8(15.4-70.0)$ \\
Number of children alive & 5.0 & 3.5 & $5(0-16)$ \\
$\quad$ Number of children & 1.3 & 1.9 & $1(0-12)$ \\
$\quad$ deceased & & & \\
Number of abortions & 0.5 & 0.9 & $0(0-5)$ \\
Weight (kg) & 54.0 & 8.7 & $53.6(36.1-85.3)$ \\
Height (cm) & 149.3 & 5.3 & $148.6(137.5-172.0)$ \\
BMl (kg m ${ }^{-2}$ ) & 24.2 & 3.3 & $24.0(17.6-35.5)$ \\
Sum of skinfold & 51.4 & 18.2 & $48.9(21.4-119.1)$ \\
$\quad$ thicknesses (mm) & & & $12.4(6.4-16.3)$ \\
Haemoglobin (g/100 ml) & 12.2 & 1.7 & $108(70-170)$ \\
SBP (mmHg) & 106.7 & 14.8 & $65(40-90)$ \\
DBP (mmHg) & 66.1 & 9.3 & \\
\hline
\end{tabular}

SD - standard deviation; BMI - body mass index; SBP - systolic blood pressure; DBP - diastolic blood pressure. women (39\%, 95\% CI: 31.8-46.9\%) were overweight. Among them, 10 (5.8\%) were overtly obese. Finally, the prevalence of anaemia in non-pregnant women (42\%, 95\% CI: 34.6-49.8\%) was 1.5 times higher than that observed at the national level. Among the 17 pregnant women, nine were anaemic (haemoglobin $<11 \mathrm{~g} / 100 \mathrm{ml})^{16}$.

\section{Children's bealth}

During the week preceding the visits, 189 children were ill (41\%, 95\% CI: 36.5-45.7\%). The main alleged causes were simple diarrhoea (20\% of children), rhinitis or pharyngitis with fever (25\%), cough without fever (13\%), and abdominal pain, nausea and vomiting (14\%). The most frequently observed clinical abnormality was dermatosis: $30 \%$ of the children suffered from pyodermatitis, scabies, impetigo or lice. Common infections such as conjunctivitis, pharyngitis and rhinitis were also frequent (about $20 \%$ ). Otitis media was observed in six children. Hypertrophy of the cervical nodes was seen in $40 \%$ of children. About 10\% of the children presented important abdominal distension. Finally, among the 460 children and adolescents examined, 286 (62\%, 95\% CI: 57.5-66.6\%) were free of clinically detectable diseases; 159 (35\%, 95\% CI: 30.2-39.1\%) suffered from mild symptoms and only 15 (3.3\%, 95\% CI: 1.8-5.3\%) from more severe illness requiring medical treatment.

Stool samples were provided by 346 children (75\%). Among them, 260 (75\%, 95\% CI: 70.2-79.6\%) were found positive for at least one helminth, 170 (49\%, 95\% CI: 43.7-54.5\%) for two forms and 60 (17\%, 95\% CI: $13.5-$ $21.0 \%)$ for three or more forms. Eggs of Ascaris lumbricoides (57\%), Trichuris trichiura (35\%) and hookworms, probably Necator americanus (7\%), were the more common forms. Larvae of Strongyloidis stercoralis (16 cases), cysts of Giardia lamblia (21 cases) and trophozoites of Balantidium coli (five cases) were also observed.

\section{Nutritional status}

A total of 454 children and adolescents (of 460) had complete anthropometric measurements. There were no cases of severe or acute malnutrition (wasting) in our population. However, the prevalence of stunting was high: 41\% (95\% CI: 33.9-49.0\%) in the 0-5-year-olds and 36\% (95\% CI: $29.4-43.9 \%$ ) in the 5-10-year-olds. Table 3 compares nutritional indices found among children under 3 years old in the present study with those of the DHS. The stunting prevalence rate was equal to that reported for rural Bolivian children. Figure 1a indicates that the weightfor-height index was close to the reference for pre-school children and above it thereafter. Weight-for-age and height-for-age indices remained low throughout infancy and childhood. Data suggest that catch-up growth did not occur in older children. Weights remained steady during childhood (between the 10th and 50th percentiles of the reference $\left.{ }^{14}\right)$, leading to elevated 
Table 2 Comparison of Beni River mothers with women at national (Bolivia) and local (Beni/Pando) level

\begin{tabular}{|c|c|c|c|}
\hline & Beni River (present survey) & Bolivia (DHS 1998*) & Beni/Pando (DHS 1998*) \\
\hline Number surveyed $(n)$ & 171 & 3239 & 182 \\
\hline Average height (cm) & $149.3 \pm 5.3 \ddagger$ & 151.0 & 153.7 \\
\hline Height $<145 \mathrm{~cm}(\%)$ & $20.1(14.1-26.6) \S$ & $12.5(11.4-13.6)$ & $3.4(1.2-7.0)$ \\
\hline$n$ & 171 & 2791 & 155 \\
\hline Average BMI $\left(\mathrm{kg} \mathrm{m}^{-2}\right)$ & $24.2 \pm 3.3$ & 25.0 & 24.9 \\
\hline $\mathrm{BMI}<18.5 \mathrm{~kg} \mathrm{~m}^{-2}(\%)$ & $2.3(0.6-5.8)$ & $0.9(0.6-1.3)$ & $0.6(0.0-3.5)$ \\
\hline $\mathrm{BMI}>25 \mathrm{~kg} \mathrm{~m}^{-2}(\%)$ & $39.2(31.8-46.9)$ & $46.4(44.5-48.2)$ & - \\
\hline$n$ & 168 & 3531 & 163 \\
\hline Severe anaemia $(\mathrm{Hb}<7.0 \mathrm{~g} / 100 \mathrm{ml})(\%) \dagger$ & $0.6(0.0-3.2)$ & $0.9(0.6-1.0)$ & $0.2(0.0-3.0)$ \\
\hline Moderate anaemia $(\mathrm{Hb}=7.0-9.9 \mathrm{~g} / 100 \mathrm{ml})(\%)$ & $7.7(4.1-12.6)$ & $5.6(4.8-6.4)$ & $3.5(1.0-7.8)$ \\
\hline Mild anaemia $(\mathrm{Hb}=10.0-11.9 \mathrm{~g} / 100 \mathrm{ml})(\%)$ & $33.9(26.8-41.5)$ & $20.7(19.3-22.0)$ & $21.0(14.8-27.9)$ \\
\hline Total anaemia (\%) & $42.2(34.6-49.8)$ & $27.2(25.7-28.7)$ & $24.7(17.6-31.2)$ \\
\hline
\end{tabular}

BMI - body mass index.

* Data are from the 1998 Demographic and Health Survey (DHS) ${ }^{6}$.

† Cut-off points refer to $\mathrm{DHS}^{6}$.

\pm Mean \pm standard deviation.

$\S$ Frequency (95\% confidence interval).

weight-for-height (0.59 \pm 0.60$)$. Adolescent BMI (average: $18.0 \pm 1.8 \mathrm{~kg} \mathrm{~m}^{-2}$ for boys and $19.4 \pm 3.6 \mathrm{~kg} \mathrm{~m}^{-2}$ for girls) was slightly under the 50 th percentile for boys and largely over for girls for a median age of 13 years $^{14}$.

\section{Risk factors for malnutrition}

There were no statistical differences between sexes in the different age groups for height-for-age; as a consequence, sexes were combined. Table 4 displays the relationships between height-for-age and categorical variables. Meanings of the codes are indicated in the table. Belonging to the Tacana ethnic group and having a high FDI were associated with significantly higher height-for-age. Among pre-school children, familial activity (as a wage earner) and absence of illness were also linked to higher heightfor-age. Interestingly, the presence of parasites did not appear to hamper growth status in any age group.

Table 5 gives values of correlation coefficients between maternal characteristics and height-for-age after adjusting for age. Mother's stature and BMI were correlated with growth status in each group. In school-age children and adolescents, the mother's adiposity was also a significant correlate. In no case was the mother's haemoglobin value correlated with height-for-age.

To further explore these results, a model was built introducing variables that produced a significant increase in variance in height-for-age. Interactions existed between the variables ethnic group and familial activity and between maternal BMI and adiposity. These variables produced a high variance inflation factor. To eliminate a potential collinearity problem, the variables familial activity and BMI were dropped. Table 6 summarises multiple regression tests between height-for-age (dependent variable) and ethnic group, FDI, parasitism, stature and adiposity of mothers (independent variables). In pre-school children, the mother's anthropometry was no longer a significant predictor, whereas ethnic group, clinical status and FDI were associated with height-for-age. In school-age children and adolescents the coefficients of determination were higher $\left(R^{2}=0.18\right.$ and 0.29 ) than in pre-school children, but in contrast maternal characteristics were significant predictors of height-for-age. Taller, more corpulent mothers had taller children. Ethnic group was a significant predictor of height-for-age in adolescents but not in school-age children.

\section{Discussion}

The findings presented here offer a contrasting view of health and nutrition. On one hand, children were free of severe acute malnutrition and only a small proportion

Table 3 Malnutrition prevalence (\%) in Beni River children less than 3 years old and comparison with children at national (Bolivia) and local (Beni/Pando) level

\begin{tabular}{lcccc}
\hline & $n$ & Stunting $(\mathrm{HAZ}<-2)$ & Wasting $($ WHZ $<-2)$ & Underweight $(\mathrm{WAZ}<-2)$ \\
\hline Beni River (present study) & 108 & $35.2(26.2-44.9) \dagger$ & $0.0(0.0-3.3)$ & $1.8(1.3-2.3)$ \\
Bolivia (all)* $_{\text {Bolivia (rural)* }}$ & 3244 & $25.6(24.0-27.1)$ & $2.4(1.6-3.4)$ & $9.5(8.5-10.5)$ \\
Beni/Pando* $^{*}$ & 1361 & $35.6(33.0-38.1)$ & $2.3(0.5-5.2)$ & $14.1(12.2-16.0)$ \\
\hline
\end{tabular}

HAZ - height-for-age Z-score; WHZ - weight-for-height Z-score; WAZ - weight-for-age Z-score.

${ }^{*}$ Data are from the 1998 Demographic and Health Survey ${ }^{6}$.

† Frequency ( $95 \%$ confidence interval). 

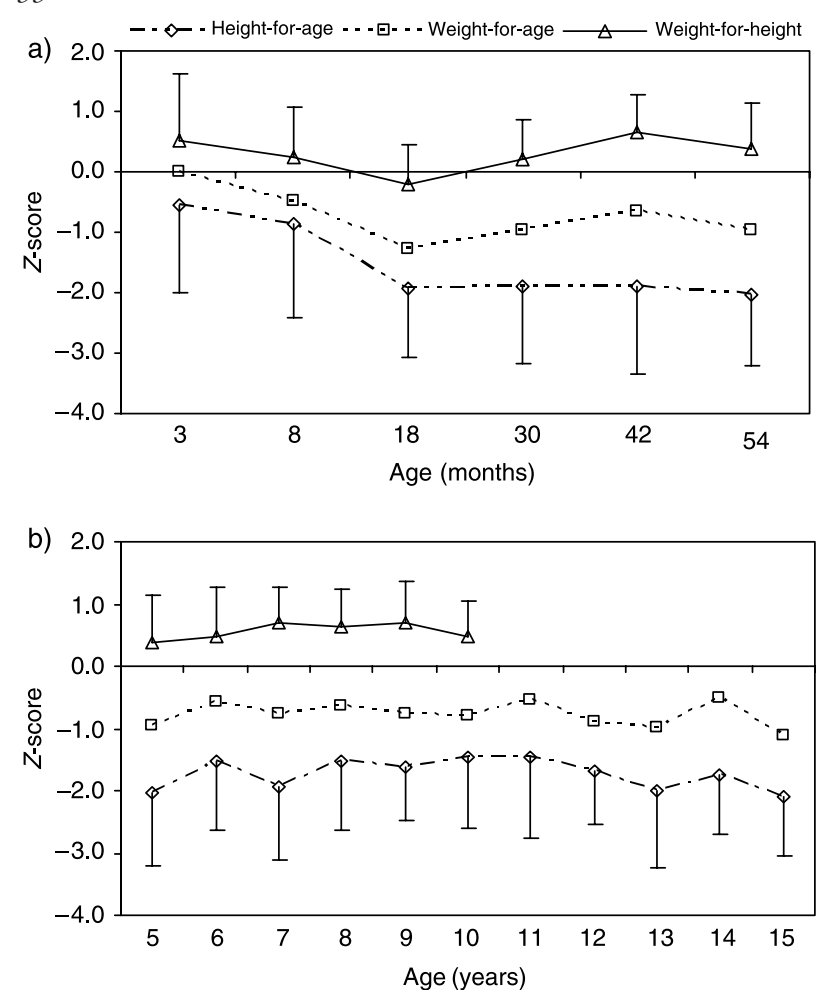

Fig. 1 Nutritional indices of $0-5$-year-olds (a) and 5-15-yearolds (b)

(3.2\%, 95\% CI: $1.8-5.3 \%)$ of subjects required medical intervention. On the other hand, the prevalence of chronic malnutrition in children was higher than that observed at national level. Furthermore, 41\% (95\% CI: 36.5-45.7\%) presented some form of illness and 75\% (95\% CI: 70.2-79.6\%) of stools examined were infested by helminths.

The low level of agricultural development in the area, along with the insufficiency of health facilities and cultural barriers, were obvious determinants of this situation. In our study, they are represented by the variable ethnic group or familial activity. The Tacana population, which was more successfully integrated into the modern market than Esse Ejjas, displayed better nutritional indicators, as did households with wage earners. The strong impact of poverty on nutritional status has already been demonstrated in this region ${ }^{5,6}$. Nevertheless, some refinements are provided by our data. Food items were the same for all subjects, but there was great variability in their combination: households with high FDI had children with higher height-for-age. FDI was obviously connected to household wealth; in pre-school children it had an independent and significant effect on height-for-age. It should be noted that high FDI entailed the presence of nutritionally valid foods like fish and milk. A recent analysis of 11 DHS surveys confirmed this association between dietary diversity and height-for-age index independently of socio-economic status ${ }^{17}$.

The presence of helminths was also widespread. A direct effect of parasites on health and nutrition could be
Table 4 Comparison of height-for-age Z-score according to different characteristics among Beni River children and adolescents

\begin{tabular}{|c|c|c|c|c|c|c|}
\hline Variable* & Group & $n$ & Mean & SD & $t$ & $P$-value \\
\hline \multicolumn{7}{|c|}{$0-4.99$-year-old children $(n=174)$} \\
\hline Ethnic group & $\begin{array}{l}1 \\
2\end{array}$ & $\begin{array}{r}148 \\
26\end{array}$ & $\begin{array}{l}-1.50 \\
-260\end{array}$ & 1.26 & 3.81 & 0.000 \\
\hline \multirow[t]{2}{*}{ Familial activity } & 1 & 159 & -1.71 & 1.44 & $2.01 \dagger$ & 0.029 \\
\hline & 2 & 15 & -1.15 & 0.97 & & \\
\hline \multirow[t]{2}{*}{ Helminths } & 1 & 72 & -1.84 & 1.52 & 1.41 & NS \\
\hline & 2 & 102 & -1.54 & 1.31 & & \\
\hline \multirow[t]{2}{*}{ Clinical state } & 1 & 96 & -1.44 & 1.40 & 2.38 & 0.018 \\
\hline & 2 & 78 & -1.94 & 1.38 & & \\
\hline \multirow[t]{2}{*}{ FDI } & 1 & 35 & -2.32 & 1.40 & 3.20 & 0.002 \\
\hline & 2 & 139 & -1.49 & 1.36 & & \\
\hline \multicolumn{7}{|c|}{ 5-9.99-year-old children $(n=177)$} \\
\hline \multirow[t]{2}{*}{ Ethnic group } & 1 & 158 & -1.50 & 1.06 & 3.97 & 0.000 \\
\hline & 2 & 19 & -2.52 & 0.82 & & \\
\hline \multirow[t]{2}{*}{ Familial activity } & 1 & 166 & -1.64 & 1.10 & 1.17 & NS \\
\hline & 2 & 11 & -1.25 & 0.87 & & \\
\hline \multirow[t]{2}{*}{ Helminths } & 1 & 121 & -1.54 & 1.07 & 1.47 & NS \\
\hline & 2 & 56 & -1.79 & 1.09 & & \\
\hline \multirow[t]{2}{*}{ Clinical state } & 1 & 110 & -1.61 & 0.99 & 0.06 & NS \\
\hline & 2 & 67 & -1.62 & 1.22 & & \\
\hline \multirow[t]{2}{*}{ FDI } & 1 & 36 & -2.03 & 1.27 & 2.54 & 0.010 \\
\hline & 2 & 141 & -1.52 & 1.01 & & \\
\hline \multicolumn{7}{|c|}{$>10$-year-old adolescents $(n=103)$} \\
\hline \multirow[t]{2}{*}{ Ethnic group } & 1 & 92 & -1.58 & 0.92 & 5.48 & 0.000 \\
\hline & 2 & 11 & -3.15 & 0.73 & & \\
\hline \multirow[t]{2}{*}{ Familial activity } & 1 & 87 & -1.68 & 1.01 & 1.02 & NS \\
\hline & 2 & 12 & -2.00 & 1.01 & & \\
\hline \multirow[t]{2}{*}{ Helminths } & 1 & 65 & -1.73 & 0.99 & 0.13 & NS \\
\hline & 2 & 38 & -1.76 & 1.08 & & \\
\hline \multirow[t]{2}{*}{ Clinical state } & 1 & 79 & -1.75 & 1.06 & -0.13 & NS \\
\hline & 2 & 24 & -1.72 & 0.91 & & \\
\hline \multirow[t]{2}{*}{ FDI } & 1 & 14 & -2.34 & 1.27 & -2.41 & 0.018 \\
\hline & 2 & 89 & -1.65 & 0.95 & & \\
\hline
\end{tabular}

SD - standard deviation; FDI - food diversity index; NS - not significant. *Variables - ethnic group: 1 = Tacana, 2 = Esse Ejjas; familial activity: 1 = agriculture, logging, fishing, $2=$ wage earner; helminths: $1=$ presence, $2=$ absence; clinical state: $1=$ good, $2=$ illness; FDI score: $1=$ low $(<10), 2=\operatorname{good}(>11)$.

† Aspin-Welch unequal variance test.

confused with factors related to poverty. However, the long-term impact of parasitism on growth has been demonstrated $^{15,18}$. The relationship between height-forage and the presence of helminths was not significant here. This is probably because the different parasitic forms were not distinguished. Morbidity from hookworms is greater than that from Trichuris and Ascaris. Giardiasis and balantidiasis are responsible for serious gastrointestinal disturbances. A recent survey carried out in the nearby area of Beni reported a high prevalence of helminths, and especially hookworms, associated with growth retardation ${ }^{19}$. A high burden of parasite infections is a common feature of Amazonian children ${ }^{20,21}$. Behavioural factors warrant consideration, as they are likely to modulate the importance and severity of helminth infestations ${ }^{22}$.

The main nutritional problem detected in children was growth retardation (stunting). This is a common observation in Latin America, where wasting prevalence is low ${ }^{23}$. Compared with other Amazonian studies, the stunting 
Table 5 Partial correlations (adjusted for age) between nutritional indices and maternal characteristics for Beni River children and adolescents

\begin{tabular}{|c|c|c|c|c|}
\hline & Maternal stature & Maternal BMI & Maternal adiposity & Maternal haemoglobin \\
\hline \multicolumn{5}{|c|}{$0-4.99$-year-old children $(n=174)$} \\
\hline Height-for-age & $0.19(0.01)^{*}$ & $0.19(0.01)$ & $0.13(0.09)$ & $-0.06(0.41)$ \\
\hline Weight-for-age & $0.12(0.12)$ & $0.20(0.01)$ & $0.14(0.07)$ & $-0.12(0.10)$ \\
\hline Weight-for-height & $-0.03(0.69)$ & $0.11(0.17)$ & $0.10(0.20)$ & $-0.11(0.15)$ \\
\hline \multicolumn{5}{|c|}{ 5-9.99-year-old children $(n=177)$} \\
\hline Height-for-age & $0.35(0.00)$ & $0.17(0.03)$ & $0.19(0.01)$ & $0.01(0.91)$ \\
\hline Weight-for-age & $0.28(0.00)$ & $0.29(0.00)$ & $0.26(0.00)$ & $-0.06(0.40)$ \\
\hline Weight-for-height & $-0.04(0.57)$ & $0.28(0.00)$ & $0.19(0.01)$ & $-0.13(0.08)$ \\
\hline \multicolumn{5}{|c|}{$>10$-year-old adolescents $(n=103)$} \\
\hline Height-for-age & $0.31(0.00)$ & $0.22(0.03)$ & $0.26(0.01)$ & $-0.06(0.58)$ \\
\hline Weight-for-age & $0.35(0.00)$ & $0.17(0.09)$ & $0.16(0.11)$ & $-0.08(0.45)$ \\
\hline $\mathrm{BMI}$ & $0.17(0.09)$ & $0.00(1.00)$ & $-0.02(0.85)$ & $-0.08(0.44)$ \\
\hline
\end{tabular}

$\mathrm{BMI}$ - body mass index.

${ }^{\star}$ Coefficient of correlation $(P$-value).

prevalence rate in our pre-school children (41\%) and school-age children (36\%) was lower than that reported for the Tsimane of Beni $(47 \%)^{7}$ and the Tukanoan and Achuar of Ecuador $(60-70 \%)^{24}$. Nevertheless, the stunting prevalence was worse than in Naporunas $(23 \%)^{25}$, Sionas-Secoya children in Ecuador $(32 \%)^{26}$ and children from Beni and Pando studied by the DHS ${ }^{6}$. Even in comparison with other Amazonian groups, the stunting prevalence was high among inhabitants along the Beni River.

Analysis by age group showed an important drop in nutritional indices by 18 months of age. Low height-forage was observed thereafter and catch-up growth was not noted in older children (Fig. 1). A similar drop was observed in weight-for-age but older children apparently recovered quickly (Fig. 1). Such a divergence between height and weight in the sequence of events was observed in other Latin American countries ${ }^{10}$, and raises questions as to the cause of stunting. Deterioration of nutritional indices corresponded to the age of weaning (16.8 months here). Growth cessation is frequently observed during the weaning period, at which an abrupt decline in dietary quality is combined with infectious attacks ${ }^{27}$. The fact that older children continued to be small is a source of concern. Tentatively, it might be suggested that the short

Table 6 Summary of multiple regression analysis between height-for-age (dependent variable) and familial and maternal characteristics (independent variables) among Beni River children and adolescents

\begin{tabular}{|c|c|c|c|c|c|}
\hline Independent variable* & $\begin{array}{l}\text { Regression } \\
\text { coefficient }\end{array}$ & SE & $t \dagger$ & $P$-value & Decision $\ddagger$ \\
\hline \multicolumn{6}{|c|}{$0-4.99$-year-old children $(n=174): R^{2}=0.145(F=4.7, P<0.0001)$} \\
\hline Ethnic group & 0.90 & 0.35 & 2.61 & 0.01 & Yes \\
\hline FDI & 0.07 & 0.04 & 2.00 & 0.05 & Yes \\
\hline Clinical status & 0.43 & 0.20 & 2.13 & 0.03 & Yes \\
\hline Helminth & -0.34 & 0.21 & 1.67 & NS & No \\
\hline Maternal adiposity & 0.00 & 0.01 & 0.11 & NS & No \\
\hline Maternal stature & -0.01 & 0.02 & 0.35 & NS & No \\
\hline \multicolumn{6}{|c|}{ 5-9.99-year-old children $(n=177): R^{2}=0.187(F=6.6, P<0.0001)$} \\
\hline Ethnic group & 0.49 & 0.27 & 1.82 & 0.07 & No \\
\hline FDI & 0.04 & 0.03 & 1.44 & NS & No \\
\hline Clinical status & -0.03 & 0.15 & 0.21 & NS & No \\
\hline Helminth & 0.08 & 0.16 & 0.53 & NS & No \\
\hline Maternal adiposity & 0.01 & 0.004 & 2.07 & 0.04 & Yes \\
\hline Maternal stature & 0.06 & 0.02 & 3.81 & 0.00 & Yes \\
\hline \multicolumn{6}{|c|}{$>10$-year-old adolescents $(n=103): R^{2}=0.29(F=6.4, P<0.0001)$} \\
\hline Ethnic group & 1.11 & 0.34 & 3.28 & 0.00 & Yes \\
\hline FDI & 0.03 & 0.03 & 0.86 & NS & No \\
\hline Clinical status & -0.01 & 0.21 & 0.06 & NS & No \\
\hline Helminth & -0.09 & 0.18 & 0.50 & NS & No \\
\hline Maternal adiposity & 0.01 & 0.01 & 1.71 & 0.09 & No \\
\hline Maternal stature & 0.04 & 0.02 & 2.18 & 0.03 & Yes \\
\hline
\end{tabular}

SE - standard error; FDI - food diversity index; NS - not significant.

${ }^{*}$ Independent variables - ethnic group = 1 (Tacana); FDI (continuous variable); clinical status = 1 (good); helminth =1 (presence); maternal adiposity is sum of four skinfold thicknesses (continuous variable); maternal stature (continuous variable). 
statures reported here were acquired early in life as a result of various health hazards; the absence of catch-up growth afterwards could result from the persistence of poor environmental conditions. Genetic influences should not be overstated since children less than 6 months of age had normal stature; the deficits appeared in older children. In addition, Tacana and Esse Ejja belong to the same linguistic family. Differences between them arose from the cultural sphere, not from their genetic background. This hypothesis is supported by multiple regression analysis. In pre-school children, height-for-age was correlated with familial and personal factors (clinical state) but not with maternal factors, contrary to the situation in older children. The association of maternal anthropometry with height-for-age of school-age children and adolescents is a reflection of an intergenerational effect of stunting. Indeed, a longitudinal survey performed in Guatemala showed that mothers who had received high energy supplements during infancy gave birth to taller children than mothers who did not receive energy supplements $^{28}$. In the same way in Chile, considerable increase of the height-for-age index was observed from one generation to the next in correlation with the spectacular economic growth of the last decade ${ }^{29}$. In less developed countries, the association between stunting and maternal stature is generally considered to be due to environmental factors ${ }^{30}$.

Maternal stature constitutes an early environmental risk factor for infants. The percentage of mothers with height less than $145 \mathrm{~cm}$ in the Beni, 20\%, is extremely high. Small maternal stature is a known risk factor for dystocia ${ }^{31}$ and low birth weight or small infant dimensions ${ }^{32}$. This point should be combined with the high childhood mortality in the area. The mortality rate is apparently higher than the under-five mortality reported for rural Bolivia (125 per $1000)^{6}$. Moreover, the presence of anaemia constitutes an additional risk for maternal and child morbidity and mortality $^{33}$. The anaemia prevalence exceeded the national level ( $42 \%$ vs. $27 \%$ ). The fact that there were no links between the low haemoglobin content of mothers and the poor nutritional status of children could be explained by the aetiology of anaemia. The main cause may not be iron deficiency but perhaps sequestration of iron in macrophages as a consequence of inflammatory processes. This point deserves further exploration.

In conclusion, this study stresses two problems. First, the precocity and probable absence of reversibility of stunting in connection with the clinical situation, as well as difficulties at the household level, call for intervention directed towards younger children. This intervention should be aimed at preventing them from catching the most common infectious and parasitic diseases. The diversity and quality of foods during the weaning period also need to be improved. Second, there exists considerable prenatal, obstetric and postnatal risk associated with the short stature of the mothers. This risk is aggravated by the presence of anaemia and is exacerbated by isolation of the communities. It is imperative that an effort be made to detect the smaller, younger women and to follow them up during pregnancy. These critical steps need to be achieved in order to prevent chronic malnutrition and its devastating consequences in the area.

\section{References}

1 Woodward A, Hales S, Litidamu N, Phillips D, Martin J. Protecting human health in a changing world: the role of social and economic development. Bulletin of the World Health Organization 2000; 78(9): 1148-55.

2 Rivera JA, Barquera S, Gonzalez-Cossio T, Olaiz G, Sepulveda J. Nutrition transition in Mexico and in other Latin American countries. Nutrition Reviews 2004; 62 S149-57.

3 Bermudez OI, Tucker KL. Trends in dietary patterns of Latin American populations. Cadernos de Saude Publica 2003; 19(Suppl. 1): S87-99.

4 de Onis M, Frongillo EA, Blossner M. Is malnutrition declining? An analysis of changes in levels of child malnutrition since 1980. Bulletin of the World Health Organization 2000; 78(10): 1222-33.

5 Larrea C, Freire W. Social inequality and child malnutrition in four Andean countries. Revista Panamericana de Salud Publica 2002; 11(5-6): 356-64.

6 Macro International Inc. Bolivia: Encuesta nacional de demografia y salud 1998 [electronic database], 1998. Available at http://www.measuredhs.com/countries/ country.cfm

7 Foster Z, Byron E, Reyes-Garcia V, Huanca T, Vadez V, Apaza L, et al. Physical growth and nutritional status of Tsimane' Amerindian children of lowland Bolivia. American Journal of Physical Anthropology 2005; 126(3): 343-51.

8 Scrimshaw NS. Historical concepts of interactions, synergism and antagonism between nutrition and infection. Journal of Nutrition 2003; 133(1): 316S-21S

9 Reyes H, Perez-Cuevas R, Sandoval A, Castillo R, Santos JI, Doubova SV, et al. The family as a determinant of stunting in children living in conditions of extreme poverty: a casecontrol study. BMC Public Health 2004; 4(1): 57.

10 Shrimpton R, Victora CG, de Onis M, Lima RC, Blossner M, Clugston G. Worldwide timing of growth faltering: implications for nutritional interventions. Pediatrics 2001; 107(5): E75.

11 Instituto Nacional de Estadística (INE). Anuario Estadístico 2001. La Paz: INE, 2001.

12 Hissink K, Hahn A. Los Tacana. Datos sobre la historia de su civilización. La Paz: Plural Editores, 2000.

13 Lohman TG, Roche A, Martorell R. Anthropometric Standardization Reference Manual. Champaign, IL: Human Kinetics Books, 1988.

14 World Health Organization (WHO). Physical Status: The Use and Interpretation of Anthropometry. Report of a WHO Expert Committee. Geneva: WHO, 1995.

15 Awasthi S, Bundy D, Savioli L. Helminthic infections. British Medical Journal 2003; 327(7412): 431-3.

16 World Health Organization (WHO). Iron Deficiency Anaemia. Assessment, Prevention and Control. A Guide for Programme Managers. Geneva: WHO, 2001.

17 Arimond M, Ruel MT. Dietary diversity is associated with child nutritional status: evidence from 11 demographic and health surveys. Journal of Nutrition 2004; 134(10): 2579-85.

18 de Silva NR. Impact of mass chemotherapy on the morbidity due to soil-transmitted nematodes. Acta Tropica 2003; 86(2-3): 197-214. 
19 Tanner S, Reyes-Garcia V, Vadez V, Huanca T, Leonard W, Mc Dade T, et al. Anthropometrics and gastrointestinal parasitic infections among the Tsimane' of Bolivia. American Journal of Human Biology 2004; 16(2): 227 [abstract].

20 Miranda RA, Xavier FB, Menezes RC. Intestinal parasitism in a Parakana indigenous community in southwestern Para State, Brazil. Cadernos de Saude Publica 1998; 14(3): 507-11.

21 San Sebastian M, Santi S. The health status of rural school children in the Amazon basin of Ecuador. Journal of Tropical Pediatrics 1999; 45(6): 379-82.

22 Fitton LJ. Helminthiasis and culture change among the Cofan of Ecuador. American Journal of Human Biology 2000; 12(4): 465-77.

23 Martorell R. Is wasting (thinness) a hidden problem in Latin America's children? Journal of Nutrition 2001; 131(4): $1133-4$.

24 Orr CM, Dufour DL, Patton JQ. A comparison of anthropometric indices of nutritional status in Tukanoan and Achuar Amerindians. American Journal of Human Biology 2001; 13(3): 301-9.

25 Buitron D, Hurtig AK, San Sebastian M. Nutritional status of Naporuna children under five in the Amazon region of Ecuador. Revista Panamericana de Salud Publica 2004; 15(3): 151-9 (in Spanish).

26 Benefice E, Barral H. Differences in life style and nutritional status between settlers and Siona-Secoya Indians living in the same Amazonian milieu. Ecology of Food and Nutrition 1991; 25: 307-22.
27 Neumann CG, Gewa C, Bwibo NO. Child nutrition in developing countries. Pediatric Annals 2004; 33(10): 658-74.

28 Stein AD, Barnhart HX, Hickey M, Ramakrishnan U, Schroeder DG, Martorell R. Prospective study of protein-energy supplementation early in life and of growth in the subsequent generation in Guatemala. American Journal of Clinical Nutrition 2003; 78(1): 162-7.

29 Amigo H, Erazo M, Bustos P. Estatura de padres e hijos Chilenos de diferente etnia y vulnerabilidad social. Salud Pública de México 2000; 42(6): 504-10.

30 Hernandez-Diaz S, Peterson KE, Dixit S, Hernandez B, Parra S, Barquera S, et al. Association of maternal short stature with stunting in Mexican children: common genes vs common environment. European Journal of Clinical Nutrition 1999; 53(12): 938-45.

31 Ould El Joud D, Bouvier-Colle MH. MOMA Group. Dystocia: a study of its frequency and risk factors in seven cities of west Africa. International Journal of Gynaecology and Obstetrics 2001; 74(2): 171-8.

32 Thame M, Wilks R, McFarlane-Anderson N, Bennett F, Forrester T. Relationship between maternal nutritional status and infant's weight and body proportions at birth. European Journal of Clinical Nutrition 1997; 51(3): 134-8.

33 Rush D. Nutrition and maternal mortality in the developing world. American Journal of Clinical Nutrition 2000; 72(Suppl. 1): 212S-40S. 